\title{
Modelling and Exhaust Nozzle Flow Simulations in a Scramjet
}

Naidu KS and Bajaj DK*

MLR Institute of Technology, Hyderabad, India

\begin{abstract}
This project will be aimed at modelling the supersonic flow inside Scramjet engine using the Computational Fluid Dynamics CFD ANSYS Fluent. Scramjet Engine starts at a hypersonic free stream Mach no. 5.00. When pressures and temperatures become so high in supersonic flight that it is no longer efficient to slow the oncoming flow to subsonic speeds for combustion, a scramjet (supersonic combustion ramjet) is used in place of a ramjet. Supersonic flow from a nozzle that represents the exhaust nozzle of a supersonic combustion ramjet SCRAMJET is modelled. Jet from the nozzle is issued into a domain which is bounded on one side by an after body wall which is parallel to the center line of the nozzle. Shocks propagating from the nozzle exit reflect from the after body. Outflow from scramjet engines can have a significant impact on both the heat transfer and the pressure distribution on the section of the aircraft that lies downstream. Most importantly, reflecting shock waves lead to large peaks in the distributions. Two geometrical configurations for the after body are tested. Experimental values are used because this span wise region is closest to the centre of the experimental model where the three-dimensional effects are minimal. Measured values of the distribution of wall pressure and heat transfer rate along the after body are used to validate the CFD simulation.
\end{abstract}

Keywords: Scramjet; Nozzle; Shock waves; Ansys; Computational fluid dynamics

\section{Introduction}

A ramjet is a form of air breathing jet engine that uses the engine's forward motion to compress incoming air without an axial compressor. A ramjet has no moving parts. Air entering the intake is compressed using the forward speed of the aircraft. The intake air is then slowed from a high subsonic or supersonic speed to a low subsonic speed by aerodynamic diffusion created by the inlet and diffuser, as seen in Figure 1. Fuel is then injected into the combustion chamber where burning takes place. The expansion of hot gases then accelerates the subsonic exhaust air to a supersonic speed. This results in a forward velocity. Ramjets work most efficiently at supersonic speeds around Mach 3 (2,284 $\mathrm{mph} ; 3,675 \mathrm{~km} / \mathrm{h})$ [1-5].

A scramjet (supersonic combusting ramjet) is a variant of a ramjet air breathing jet engine in which combustion takes place in supersonic airflow. As in ramjets, a scramjet relies on high vehicle speed to forcefully compress the incoming air before combustion, but a ramjet decelerates the air to subsonic velocities before combustion, while airflow in a scramjet is supersonic throughout the entire engine. Scramjets on the other hand do not slow the free stream air down through the combustion chamber rather keeping it at some supersonic speed. This allows the scramjet to operate efficiently at extremely high speeds: theoretical projections place the top speed of a scramjet between Mach $12(8,400 \mathrm{mph} ; 14,000 \mathrm{~km} / \mathrm{h})$ and Mach 24 $(16,000 \mathrm{mph} ; 25,000 \mathrm{~km} / \mathrm{h})$.

Keeping the free stream flow supersonic enables the scramjet to fly at much higher speeds. Supersonic flow is needed at higher speeds to maximize efficiency through the combustion process (Figure 2).

\section{Theory of a scramjet}

All scramjet engines have fuel injectors, a combustion chamber, a thrust nozzle and an inlet, which compresses the incoming air. Sometimes engines also include a region which acts as a flame holder (a component of a jet engine designed to help maintain continual combustion), although the high stagnation temperatures mean that an area of focused waves may be used, rather than a discrete engine part as seen in turbine engines. Other engines use pyrophoric (a substance that ignites spontaneously) fuel additives, such as saline, to avoid such concerns.

An isolator between the inlet and combustion chamber is often included to improve the homogeneity of the flow in the combustor and to extend the operating range of the engine. A scramjet is reminiscent of a ramjet. In a typical ramjet, the supersonic inflow of the engine is decelerated at the inlet to subsonic speeds and then reaccelerated through a nozzle to supersonic speeds to produce thrust. This deceleration which is produced by a normal shock (a type of propagating disturbance), creates a total pressure loss which limits the upper operating point of a ramjet engine.

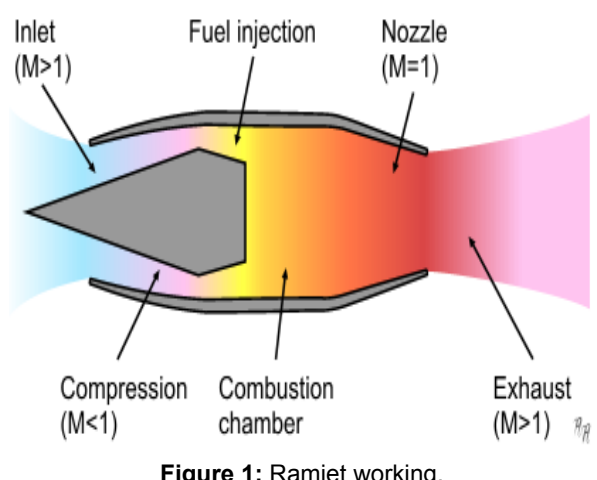

*Corresponding author: Bajaj DK, Assistant Professor Of Aerospace Engineering PG. Scholar (Aero), MLR Institute of Technology, Hyderabad, India, Tel: 098667 55166; E-mail: dineshbajaj113@gmail.com

Received July 01, 2015; Accepted August 26, 2015; Published September 05, 2015

Citation: Naidu KS, Bajaj DK (2015) Modelling and Exhaust Nozzle Flow Simulations in a Scramjet. J Astrophys Aerospace Technol 3: 122. doi:10.4172/23296542.1000122

Copyright: $\odot 2015$ Naidu KS, et al. This is an open-access article distributed under the terms of the Creative Commons Attribution License, which permits unrestricted use, distribution, and reproduction in any medium, provided the original author and source are credited. 


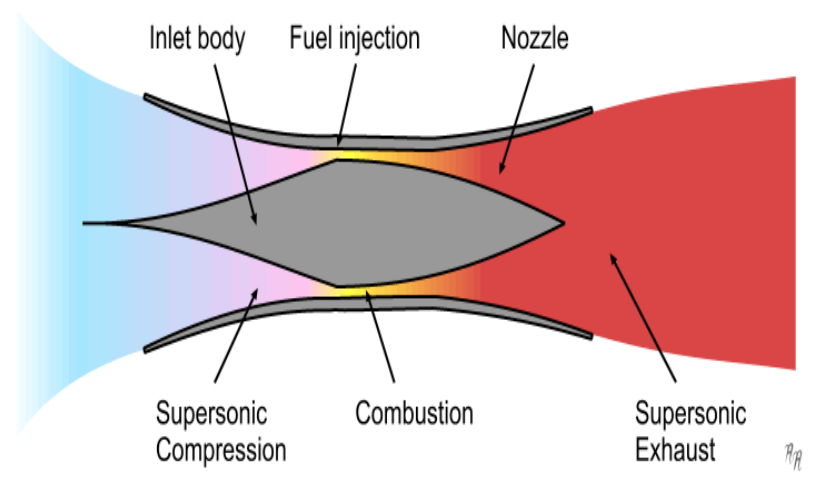

Figure 2: Scramjet working

For a scramjet, the kinetic energy of the free stream air entering the scramjet engine is large compared to the energy released by the reaction of the oxygen content of the air with fuel hydrogen. Thus the heat released from combustion at Mach 25 is around $10 \%$ of the total enthalpy of the working fluid. Thus the design of a scramjet engine is as much about minimizing drag as maximizing thrust. Therefore, throttling of the entrance to the thrust nozzle is not a usable control technique. In effect, a block of gas entering the combustion chamber must mix with fuel and have sufficient time for initiation and reaction, all the while travelling supersonically through the combustion chamber, before the burned gas is expanded through the thrust nozzle. This places stringent requirements on the pressure and temperature of the flow, and requires that the fuel injection and mixing to be extremely efficient. Usable dynamic pressures lie in the range 20 to $200 \mathrm{kPa}(0.2-2$ bar),

$$
\mathrm{q}=1 / 2 \rho v^{\wedge} 2
$$

Where $q$ is the dynamic pressure of the gas, $\rho$ (rho) is the density of the gas, $v$ is the velocity of the gas.

\section{Features that scramjets inlets will likely contain}

- All of the design surfaces are used to compress the flow, resulting in a complicated 3D shock system.

- Adjustable surfaces and variable geometry are used to support flights from supersonic to hypersonic speeds.

- The inlet through the use of an isolator will have to be compatible with the combustion pressure rise.

- The inlet must be integrated with the fuselage design to accommodate the long compression ramps.

- Finally, the inlet will be arranged in a single segment or in several.

\section{Methodology}

Flow simulation solves the governing equations with the finite volume method on a spatially quadrilateral computational mesh designed in the Cartesian coordinate system with the planes orthogonal to its axes and refined locally at the solid/fluid interface and in the fluid region during calculation. The governing equations are discretized in a conservative form due to the finite volume method. The governing equations are integrated over a control volume which is a grid cell, and then approximated with the cell-centred values of the physical variables. The spatial derivatives are approximated with implicit difference operators of second-order accuracy. The time derivatives are approximated with an implicit first-order Euler scheme. The numerical solution technique uses stages to create a locally refined quadrilateral computational mesh and used then for solving the governing equations on it. The meshing procedures are performed before the calculation. The first procedure uses partial cells for near wall conditions to monitor heat and mass fluxes; and uses a basic rectangular mesh, which is determined by the computational domain and not dependent on the solid/fluid interface. The next stage allows cells to either merge or split further to refine the mesh at the solid/fluid interface curvatures. The final stage allows the mesh to be refined by using a narrow channel criterion. This results in cells being merged in low gradient regions and splitting of cells in high-gradient regions. The algorithmic parameters are stated to be velocity, temperature, density, turbulent energy, turbulent dissipation rate, and component concentrations in fluid mixtures. The numerical algorithm in Flow Simulation solves for fully implicit discrete convection/diffusion equations. These equations obtain the intermediate values of momentum and the final values of turbulent parameters, temperature, and species concentrations. The pressure correction and a final momentum field are combined to satisfy the discrete fully implicit continuity equation. In order to decrease the solution time, Flow Simulation uses a technique called the multi-grid method. Given the mesh, a sequence of grids (grid levels) is constructed, with decreasing nodes. On every such grid, the residual of the associated system of algebraic equations is restricted to a coarser grid level, forming the right hand side of the system on that grid. When the solution on the coarse grid is computed, it is interpolated to the finer grid and used there as a correction to the result of the previous iteration.

\section{CFD models}

$0^{\circ}$ After body, with wedge shock generator configuration shown below implies that one parallel to the nozzle centreline called the $0^{\circ}$ after body. Provision was made for mounting shock wave generators on the cowl lip. With the $0^{\circ}$ afterbody a shock generator inclined $3^{\circ}$ to the nozzle axis was used (Figure 3a and 3b) (Tables 1 and 2).

\section{CFD meshing}

Two-dimensional grids were made for the test of the $0^{\circ}$ geometry. The CFD mesh was a39230-cell mesh made entirely out of quadrilateral cells. For the $20^{\circ}$ geometry, a single quadrilateral 36270-cell mesh was made (Figures $4 \mathrm{a}$ and $4 \mathrm{~b}$ ).

\section{Results and Discussions}

The 2-D contour plots for flow variables as obtained from FLUENT

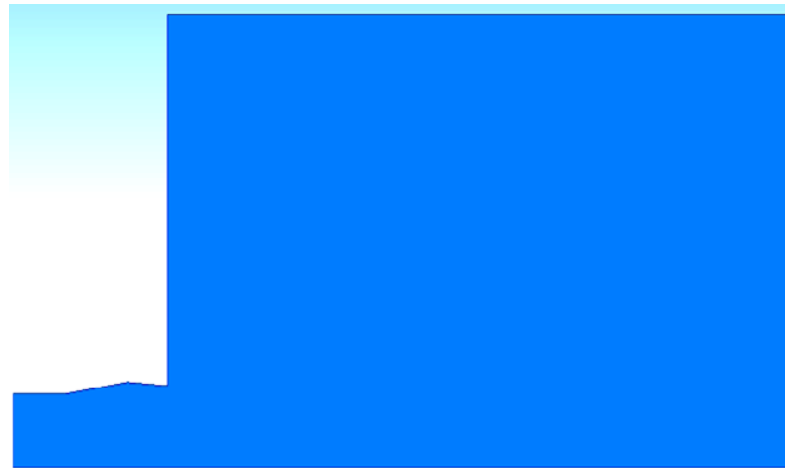

Figure 3a: $0^{\circ}$ after body with wedge. 
Citation: Naidu KS, Bajaj DK (2015) Modelling and Exhaust Nozzle Flow Simulations in a Scramjet. J Astrophys Aerospace Technol 3: 122. doi:10.4172/2329-6542.1000122

Page 3 of 6

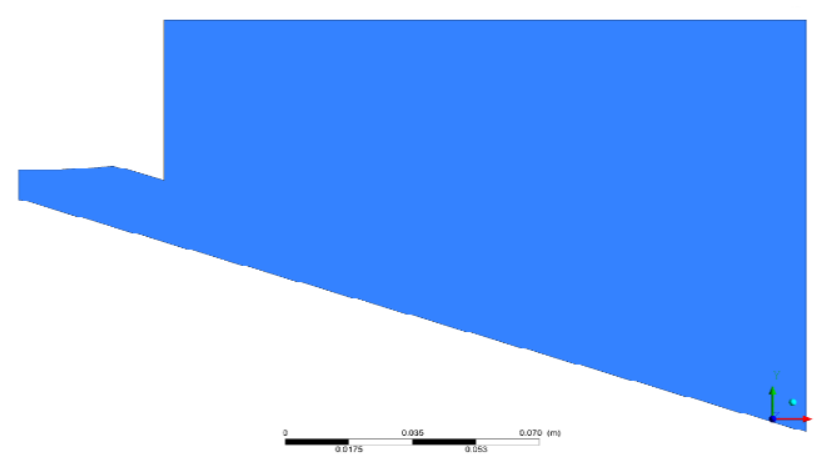

Figure 3 b: $20^{\circ}$ after body with wedge.

\begin{tabular}{|c|c|}
\hline Property & Dimension \\
\hline Nozzle outlet diameter $(\mathrm{cm})$ & 1.5 \\
\hline Length of cowl $(\mathrm{cm})$ & $3.5 \mathrm{D}$ \\
\hline
\end{tabular}

Table 1: Geometric properties.

\begin{tabular}{|c|c|}
\hline Boundary Conditions & values \\
\hline Inlet Total Pressure (gauge) & $551600 \mathrm{~Pa}$ \\
\hline Inlet Static Pressure (gauge) & $127100 \mathrm{~Pa}$ \\
\hline Inlet Total Temperature & $477.8 \mathrm{~K}$ \\
\hline Inlet Turbulent Intensity & $2 \%$ \\
\hline Wall temperature & $328 \mathrm{~K}$ \\
\hline Outlet Pressure (gauge) & $2780 \mathrm{~Pa}$ \\
\hline
\end{tabular}

Table 2: Boundary conditions.

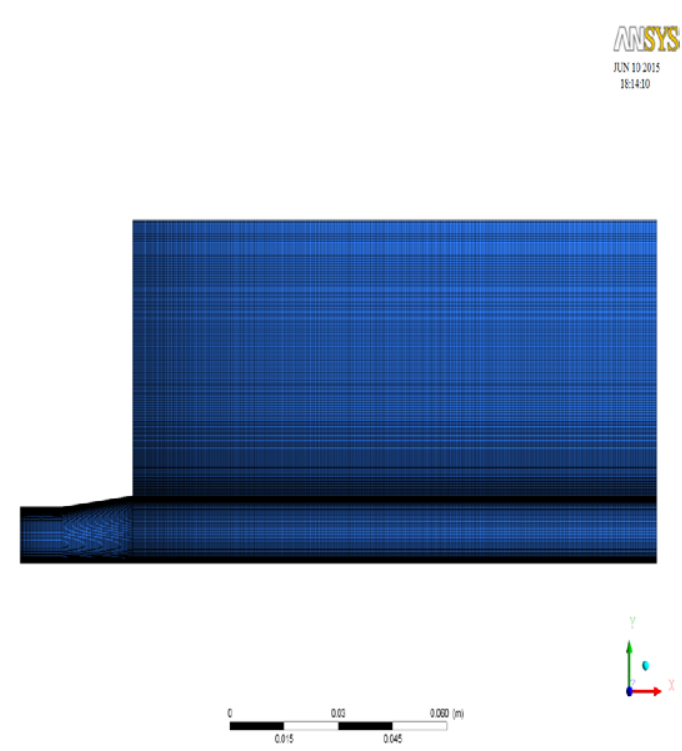

Figure 4a: Quadrilateral grid for $0^{\circ}$ after body.

for the supersonic Flow case have been presented for Mach number, static pressure and static temperature. The pressure contours for the $0^{\circ}$ after body using an adapted quadrilateral mesh. Normalized pressure is maximum at the nozzle end of about $130.1 \mathrm{kpa}$, exhaust gas as it moves away from the nozzle end normalized pressure around $70 \mathrm{kpa}$ (Figures 5a-5l). Pressure variation along the centreline $0^{\circ}$ after body with wedge as a function of horizontal distance. The reflecting shock on the after body leads to a large jump in both pressure and Temperature. Pressure concentration near wedge is maximum as observed in the Figure 6 because of $0^{\circ}$ after body inclination with respect to the nozzle axis. The thrust generation is minimum due to reflecting shock on the afterbody narrow to the shock generator. All are in excellent agreement with experimental data.

Across the wedge pressure again reduces because of $20^{\circ}$ after body inclination with respect to nozzle axis. Shock waves generate from the wedge impinging on after body and these shock waves is much more diffuse by the time it reflects off the after body (Figure 7).

Compares pressure ratio as a function of horizontal distance for the experimental results and simulated results of $0^{\circ}$ after body with wedge. All are in excellent agreement. Pressure is normalized by the entrance value, Pe (Figure 8a-8c).

\section{Conclusion}

By this Analysis we can conclude the "K epsilon turbulence model exactly simulates the flow field characteristics in supersonic and hypersonic conditions" in capturing shocks at leading edges and shock

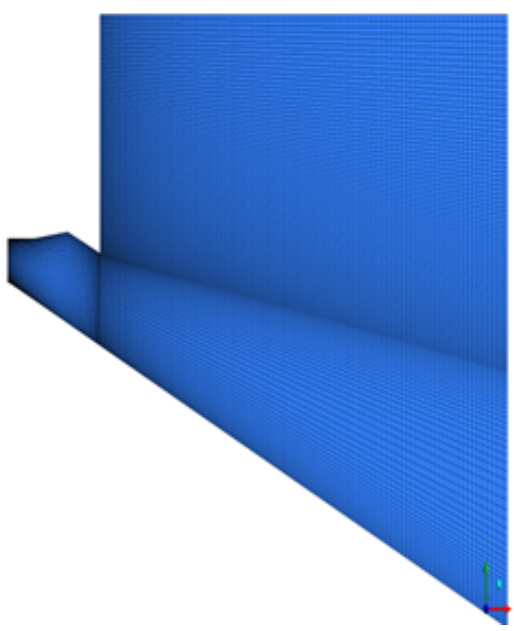

Figure 4b: Quadrilateral grid for $20^{\circ}$ after body

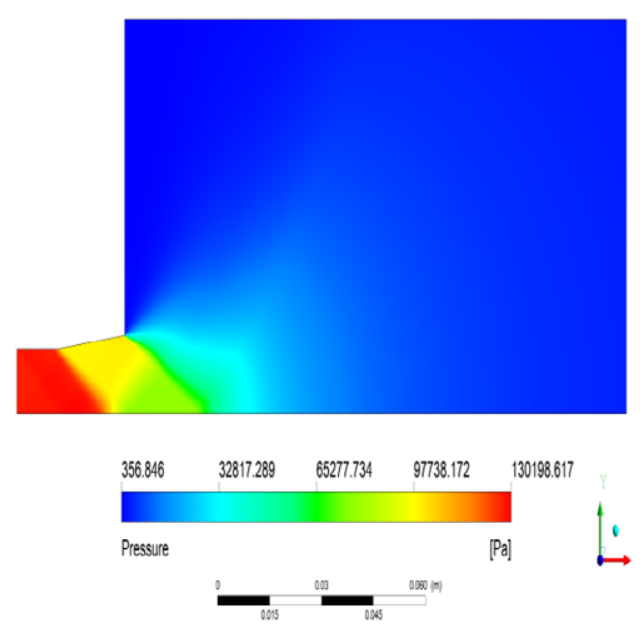

Figure 5a: Pressure contours $0^{\circ}$ after body with no wedge. 
Citation: Naidu KS, Bajaj DK (2015) Modelling and Exhaust Nozzle Flow Simulations in a Scramjet. J Astrophys Aerospace Technol 3: 122. doi:10.4172/2329-6542.1000122

Page 4 of 6

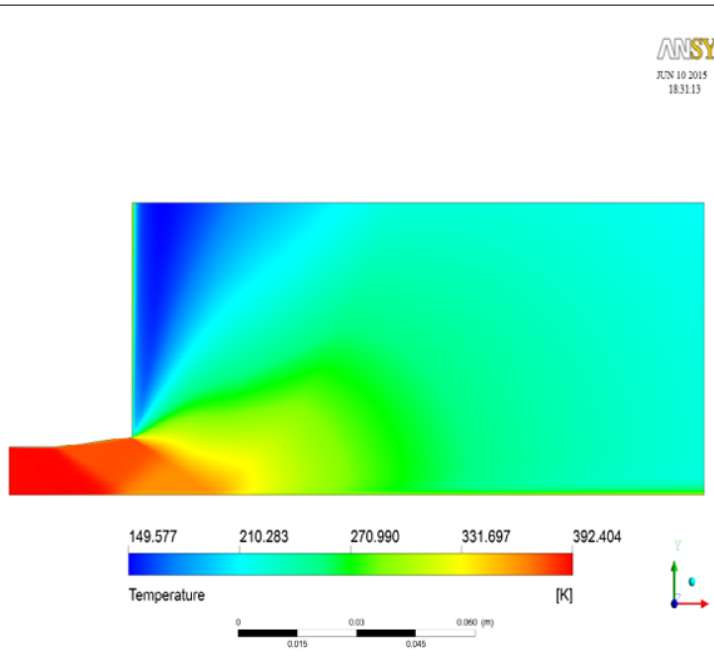

Figure 5b: Temperature contours $0^{\circ}$ after body with no wedge.

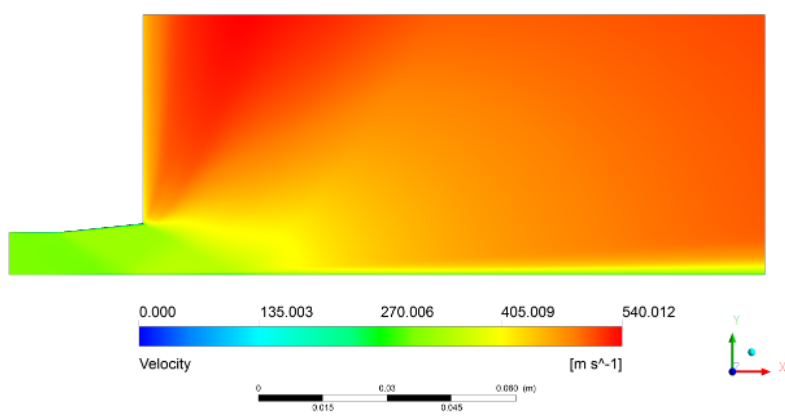

Figure 5c: Velocity contours $0^{\circ}$ after body with no wedge
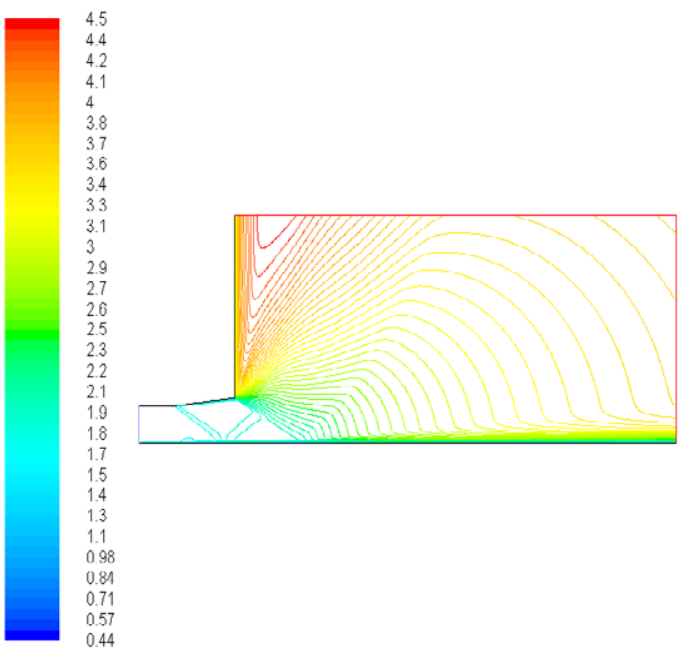

Figure 5d: Mach number Contours $0^{\circ}$ after body with no wedge. trains in the isolator. Supersonic flow from a nozzle that represents the exhaust nozzle of a supersonic combustion ramjet (SCRAMJET) is modelled using ANSYS Fluent. Jet from the nozzle is issued into a domain which is bounded on one side by an after body wall which is parallel to the centreline of the nozzle. Shocks propagating from the nozzle exit reflect from the after body. Measured values of (i) the distribution of wall pressure and (ii) heat transfer rate along the after body are used to validate the CFD simulation.

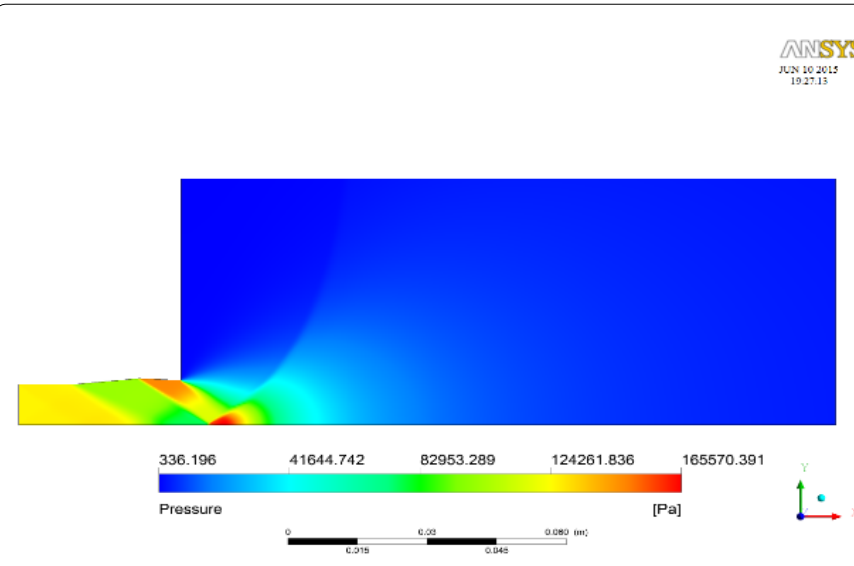

Figure 5e: Pressure contours $0^{\circ}$ after body with wedge.

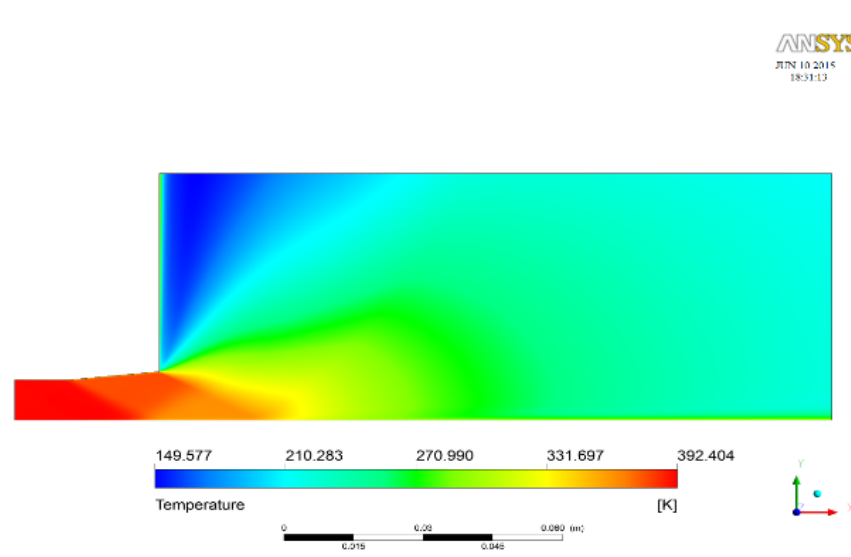

Figure 5f: Temperature contours $0^{\circ}$ after body with wedge.

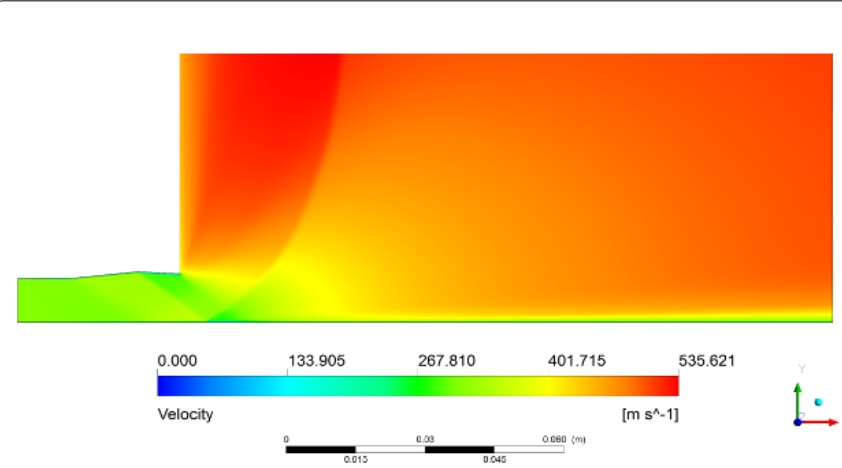

Figure 5g: Velocity contours $0^{\circ}$ after body with wedge. 
Citation: Naidu KS, Bajaj DK (2015) Modelling and Exhaust Nozzle Flow Simulations in a Scramjet. J Astrophys Aerospace Technol 3: 122. doi:10.4172/2329-6542.1000122

Page 5 of 6
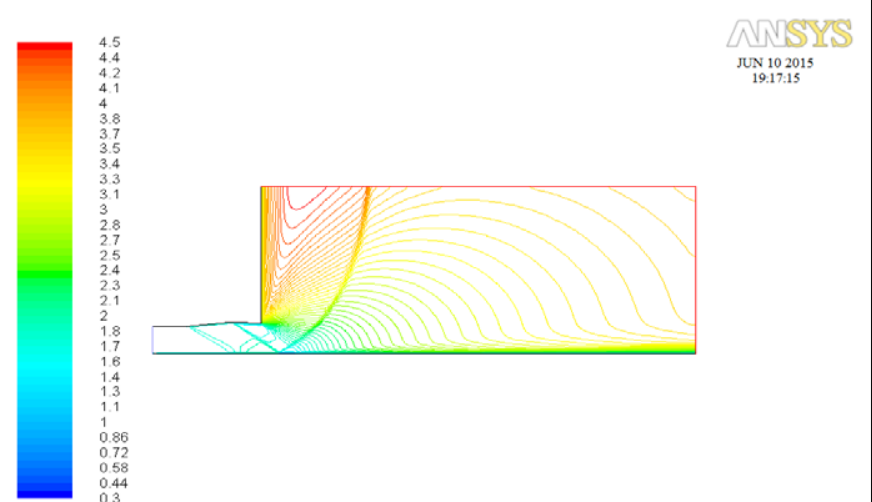

Figure 5h: Mach number contours $0^{\circ}$ after body with wedge.

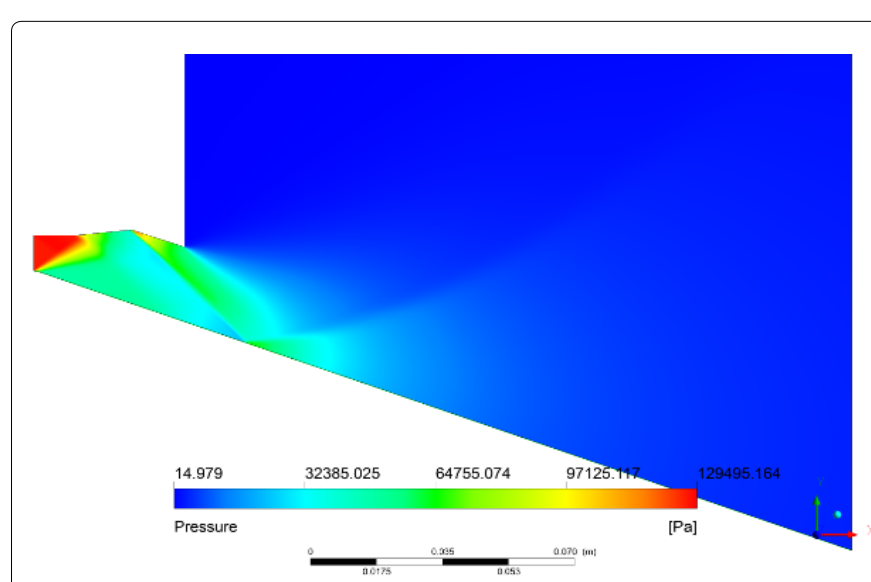

Figure 5i: Pressure contours $20^{\circ}$ after body with wedge.

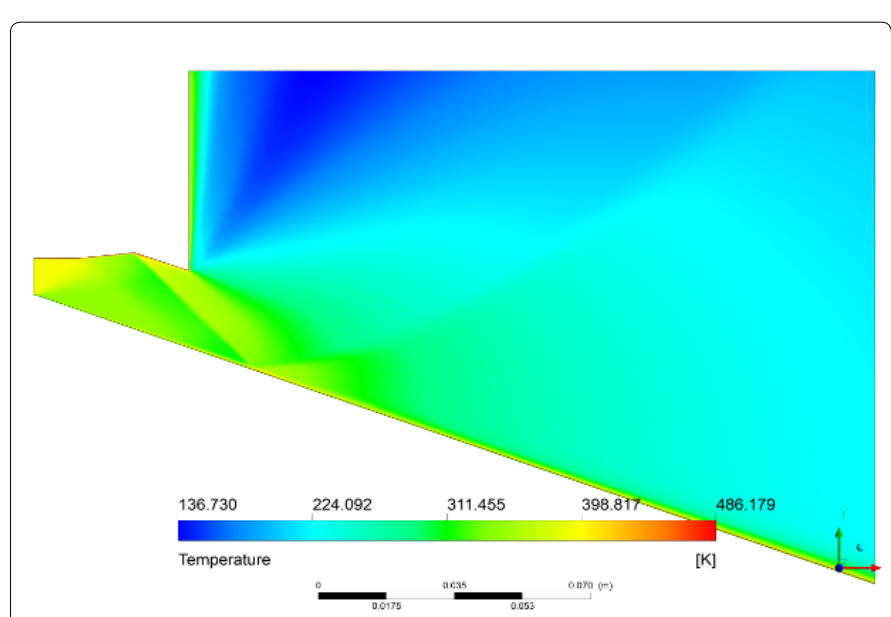

Figure 5j: Temperature contours $20^{\circ}$ after body with wedge.

It is interesting to note that obtaining experimental pressure measurements was a quicker process than CFD modelling in terms of both overall time taken and the time to investigate each configuration. However, CFD generates a much larger number of flow parameters than can be experimentally determined and is significantly less expensive, in terms of both personnel and equipment, than performing experiments in the shock tunnel. Simulation has been validated for a two- dimensional scramjet outlet flow. In particular, we compared pressures and heat transfer on the after body for $0^{\circ}$ and $20^{\circ}$ configurations.

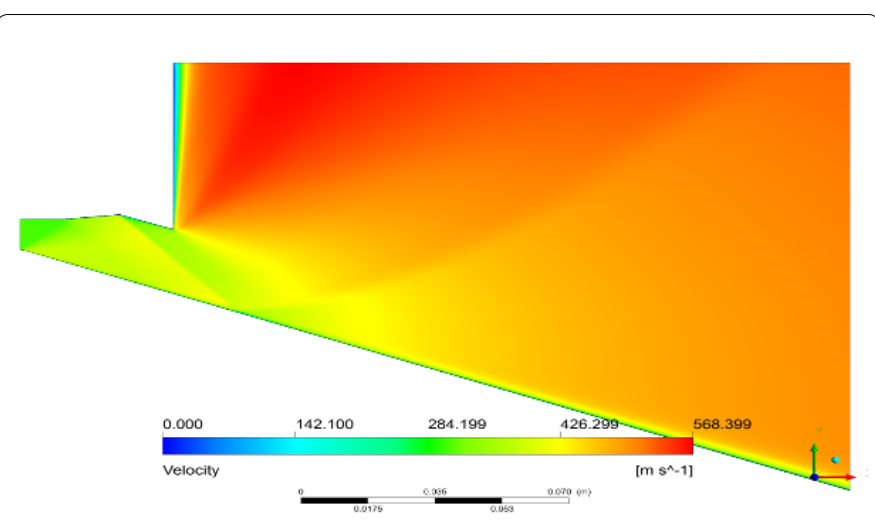

Figure 5k: Velocity contours $20^{\circ}$ after body with wedge.
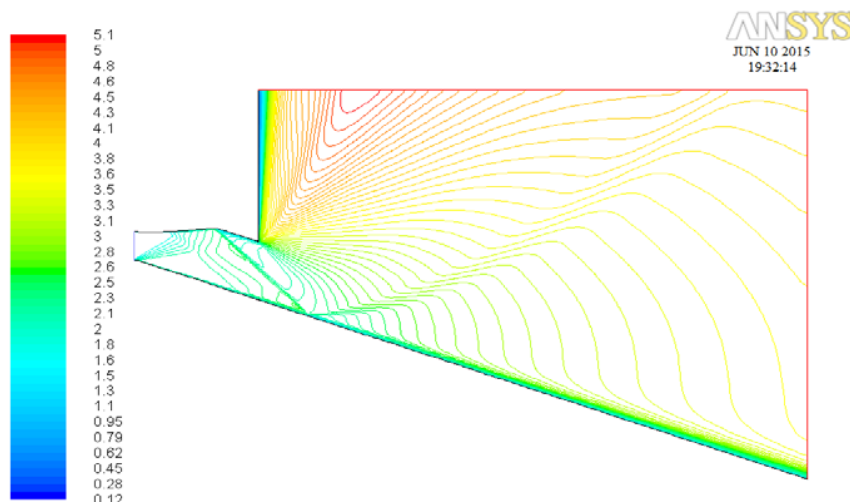

Figure 5I: Mach number contours $20^{\circ}$ after body with wedge.

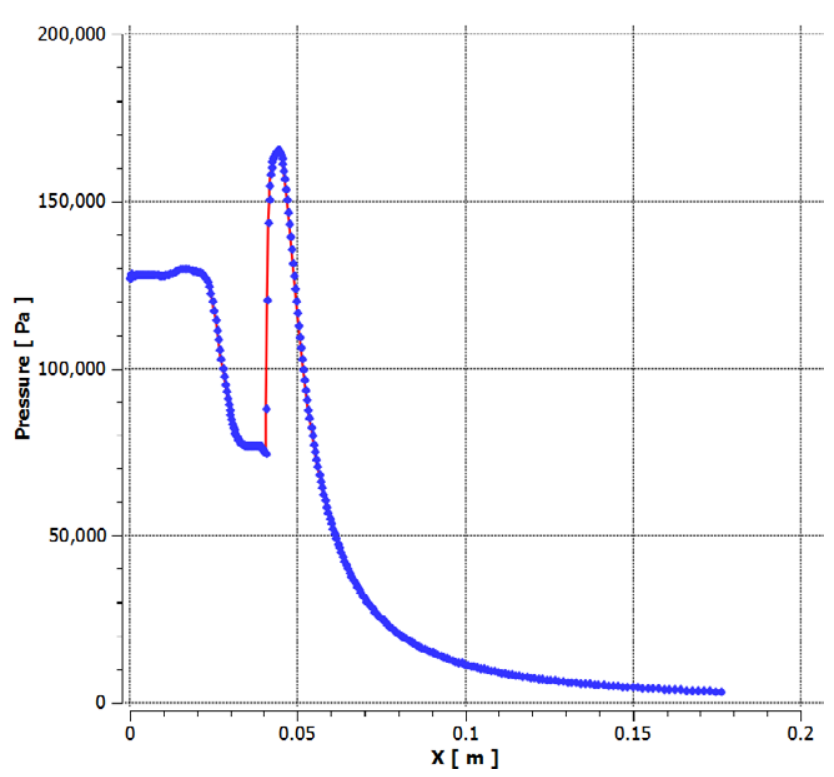

Figure 6: Pressure variation along the centreline $0^{\circ}$ after body with wedge. 
Citation: Naidu KS, Bajaj DK (2015) Modelling and Exhaust Nozzle Flow Simulations in a Scramjet. J Astrophys Aerospace Technol 3: 122. doi:10.4172/2329-6542.1000122

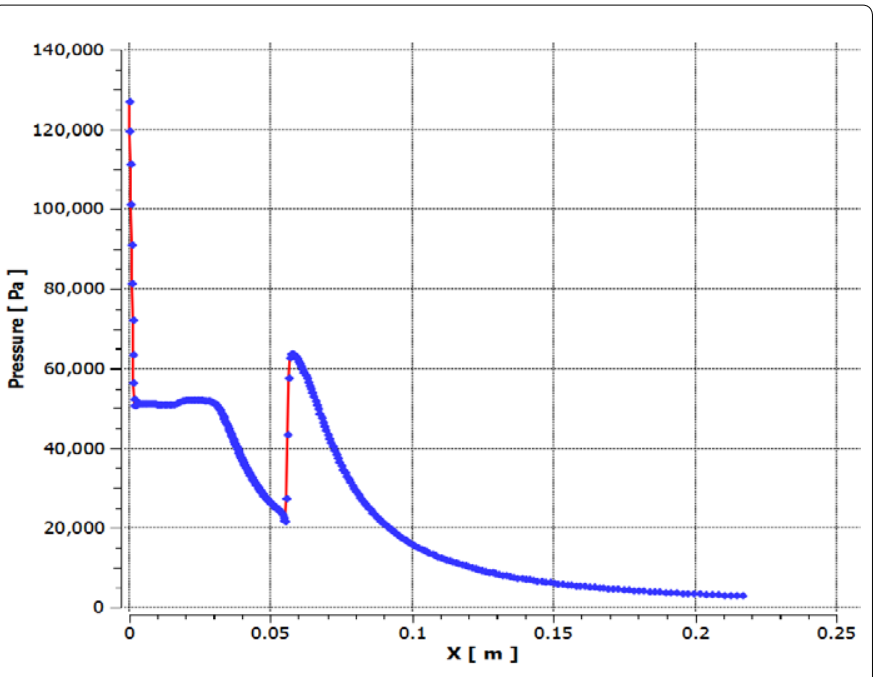

Figure 7: Pressure variation along the centreline $20^{\circ}$ after body with wedge.

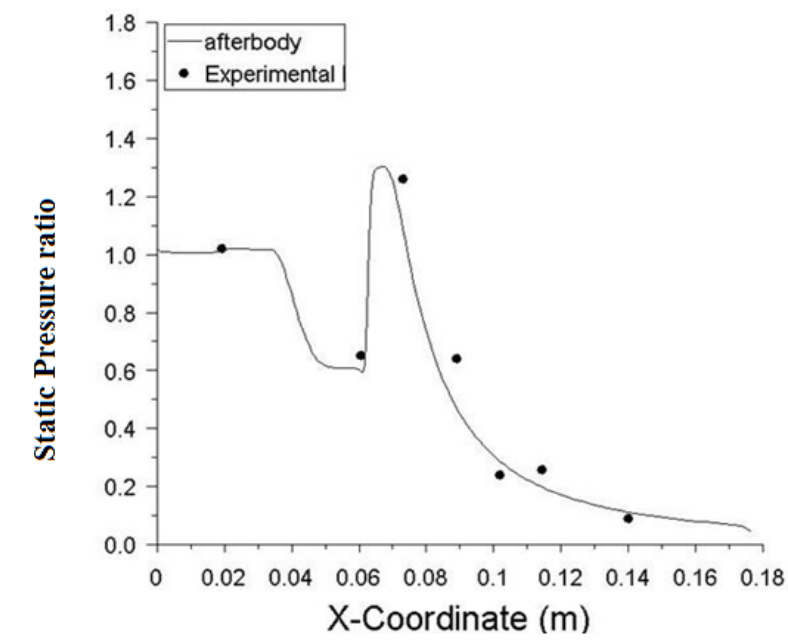

Figure 8a: Comparison of predicted static pressure distribution on the $0^{\circ}$ after body with experimental data.

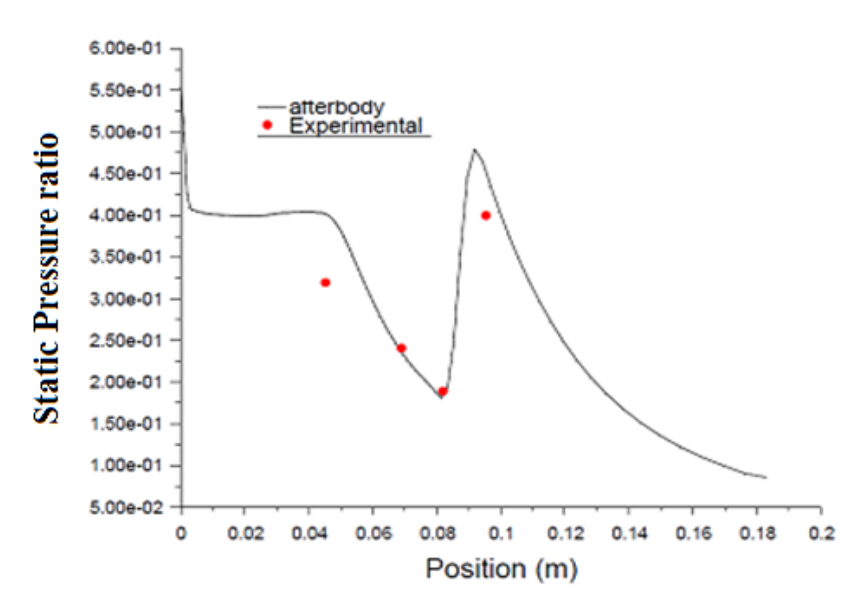

Figure 8b: Comparison of predicted static pressure distribution on the $20^{\circ}$ after body with experimental data.

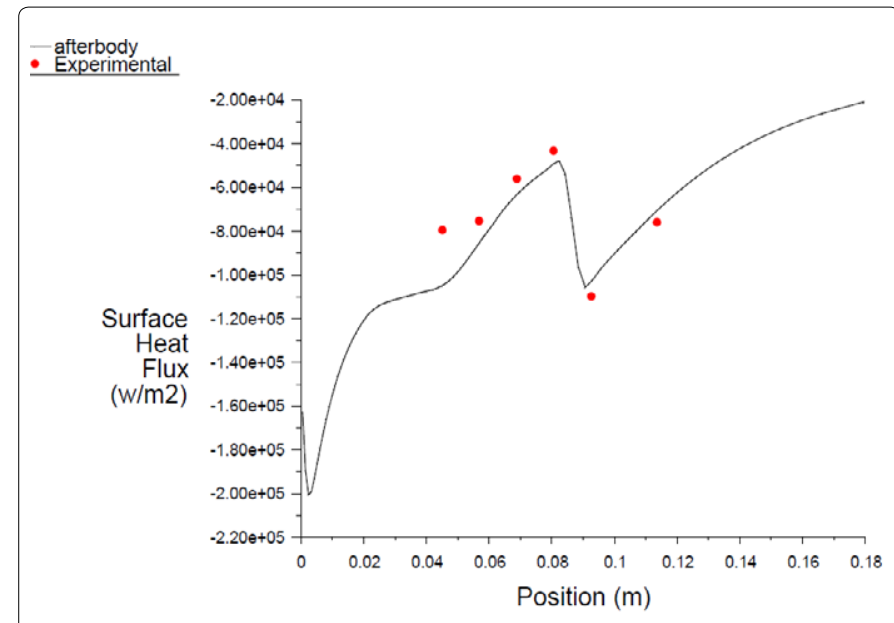

Figure 8c: Comparison of predicted total heat flux along the $20^{\circ}$ after body with experimental data.

\section{Future Work}

The first of these is that analysing three dimensional scramjet and the next is application of a fully designed expansion system employing the use of method of characteristics or CFD codes. This will enable more precise calculations of performance, as well as provide more realistic overall engine lengths to be obtained, as the nozzle does not have to be fully expanded to free stream conditions to gain a satisfactory amount of thrust. As for the practical design of this scramjet, the use of cavitybased fuel injectors should be explored.

This project looked at a two dimensional model of the Scramjet exhaust. The logical extension to this would be to use a three dimensional model, Also the shock waves produce on the side walls could be captured. Three dimensional models would be impractical unless a CFD package with shock-capturing features could be used.

\section{References}

1. Pandey KM, Sivasakthivel T (2011) CFD Analysis of a Hydrogen Fuelled Mixture in Scramjet Combustor with a Strut Injector by Using Fluent Software. IACSIT International Journal of Engineering and Technology 3: 109-115.

2. Cubbage JM, Monta WJ (1991) Parametric Experimental Investigation of a Scramjet Nozzle at Mach 6 with Freon and Argon or Air Used for Exhaust Simulation. NASA TP 3048

3. Pecnik R, Terrapon VE, Ham F, laccarino G (2009) Full system scramje simulation. Center for Turbulence Research Annual Research Briefs 33-45.

4. Huang W, Qin H, Luo S, Wang Z (2010) Research status of key techniques for shock-induced combustion ramjet (scramjet) engine. Science China Technological Sciences 53: 220-226.

5. Tatum KE, Huebner LD (1995) Exhaust Gas Modelling Effects on Hypersonic Powered Simulation at Mach 10. AlAA Sixth International Aerospace Planes and Hypersonic Technologies Conference, Chattanooga, TN, AIAA 95-6068. 